\title{
Internet addiction in school going adolescents of different socio economic classes in Western India
}

\author{
Mane S. ${ }^{1}$, Salunkhe S. ${ }^{2}$, Batta M. ${ }^{3}$, Agarkhedkar S. ${ }^{4}$, Kumar G. ${ }^{5}$, Bharaswadkar R. ${ }^{6}$ \\ ${ }^{1}$ Dr. Shailaja Mane, Professor, ${ }^{2}$ Dr. Shradha Salunkhe, Assistant Professor, ${ }^{3}$ Dr. Manu Batta, Junior Resident, ${ }^{4}$ Dr. Sharad \\ Agarkhedkar, Professor and Head of Department, ${ }^{5}$ Dr. Gaurav Kumar, Senior Resident, ${ }^{6}$ Dr Rasika Bharaswadkar, \\ Assistant Professor, all authors are attached with Department of Pediatrics, Dr. D. Y. Patil Vidyapeeth, Pimpri, Pune, \\ Maharashtra, India.
}

Corresponding Author: Dr. Shradha Salunkhe, Department of Pediatrics, Assistant Professor, Dr. D.Y. Patil Medical College, Pimpri, Pune, E-mail Id: salunkheshradha@gmail.com

\begin{abstract}
Background: Adolescents use internet as the primary medium for communication and socialization. But excessive use of internet may affect family and interpersonal relationships, academic performance and emotional development among adolescents. Excessive and incorrect use of internet is identified as Internet Addiction (IA). The present study was conducted to assess the pattern of internet use among school going adolescents of different socio-economic status as there are growing concerns worldwide for internet addiction. Methods: After taking consent of school principal, students were given a questionnaire for socio-demographic details. Internet addiction test (IAT) was explained to them. Results: In this study maximum number of children had moderate (50-79) level of internet addiction test score i.e. 317 (63.4\%), 120 (24\%) were in mild (20-49) level of internet addiction test score, $56(11.2 \%)$ were in severe (80 - 100) level of internet addiction test score. Internet addiction is more common in boys than girls. Socio economic class II children had significantly more internet addiction score thanclass III andIV in study group $(\mathrm{p}<0.0001)$. Conclusion: In this study, prevalence of internet addiction is high among boys of 12 to 17 years. Internet addiction should be lowered with the help of media literacy. As addiction of media is increasing, there is an urgentneed to use a comprehensive approach combining periodical awareness to the students and parents andincorporating good practices of internet use.
\end{abstract}

Keywords: Internet addiction, Adolescents, Internet addiction test (IAT)

\section{Introduction}

Internet has exploded to become a daily part of our lives. For the majority of individuals, the internet represents an incredible information tool and unquestionable opportunity for social connectedness, self-education, economic betterment, and freedom from shyness and paralyzing inhibitions. For them, the internet enhances their well-being and quality of life. For others, it can be used by some to indulge in pornography, excessive gaming, chatting for long hours, and even gambling. There have been growing concerns world wide for what has been labeled as "internet addiction"[1].

Scenario of internet use: There is spurt growth of internet users worldwide. There are around 7 billion internet users till June 2016, out of which Asia has got 4

Manuscript received: $17^{\text {th }}$ January 2018

Reviewed: $27^{\text {th }}$ January 2018

Author Corrected: $3^{\text {rd }}$ February 2018

Accepted for Publication: $7^{\text {th }}$ February 2018 billion. India being next to China in Asian countries which got 462 million internet users as compared to 137 million in year 2000. Thus the internet penetration in India is $36.5 \%$ of population [2].

This rapid expansion and proliferation of the internet has provided better opportunities for communication, information and social interaction. However, the excessive undisciplined use by some individuals has led to the emergence of the internet addiction.

Internet addiction (IA) is an upcoming and less researched entity especially in developing countries like India. The term "internet addiction" was proposed by Dr. Ivan Goldberg in 1995 for pathological compulsive internet use [3]. Internet addiction commonly refers to an individual's inability to control his or her use of the internet (including any online-related, compulsive behavior), which eventually causes one's marked 
Editorial

distress and functional impairment in daily life. Research studies in the Western and Asian contexts suggest that the risk of Internet addiction among young people is increasing [4]. Yang believed that addiction is applicable to internet users, because internet addiction symptoms are the same as those in alcohol and drug addiction [5].

Several risk factors have been identified as determinants of internet addiction including: being male, living in metropolitan areas, not living with biological parents, low parental involvement, parental unemployment [6], low educational level of parents. Other risk factors includeyoung age while using internet for the first time, overusing of social and game network sites etc[7].

Another important factor that influences the internet use are smart phones which has brought easy accessibility, replacing the powerful cables. In addition to use of mobile phone for communication, people used cell phone formany features such as games, access to the internet and social networks, messaging, videos, multimedia, calculator, alarm clock, and navigation etc $[8,9]$. Due tolack of parental control and feeling of independence, adolescents and young adults are at high risk of behavioral addictions. In last few years, number of internet users, both broadband and mobile users has rapidly increased in India and large numbers of them are adolescents [10]. The present study was conducted to assess the pattern of internet use among school going adolescent students of different socio-economic status.

\section{Materials and Methodology}

Aims and Objectives- This study was done to find out the prevalence of internet addiction among school going students of 12 to 17 years of age from different socio economic classes.

Study settings- This study was conducted in 500 students, of 12 to 17 years age group from different schools of different streams in Pune, Maharashtra, India from August 2016 to January 2017. Prior permission of study was taken from these schools. Written informed accent was obtained for the participation in the study from the students individually.

Study Design- Prospective, Cross-sectional, Observational study

\section{Inclusion Criteria}

1. School going adolescents of 12 to 17 years of age.

2. Adolescents who were willing to participate in the study.

\section{Exclusion Criteria}

1. Adolescents below and above 12 to 17 years of age.

2. Adolescents who were not willing to participate in the study

\section{Study Tools}

1. Socio-Demographic Proforma.

2. The Internet Addiction Test (IAT; Young, 1998): is a 20 item 5-point Likert scale that measures the severity of self-reported compulsive use of the internet.

\section{Methodology}

A questionnaire for socio-demographic details like age, sex, residence was collected. Internet addiction test (IAT) was explained. Internet Addiction Test (IAT) with English version of IAT was used in this study. The Internet Addiction Test (IAT) is the first validated instrument to assess internet addiction. The psychometric properties of the IAT shows that it is reliable and valid measure that has been used in further research on internet addiction [11].

The test measures the extent of client's involvement with the computer and classifies the addictive behavior in terms of mild, moderate and severe impairment. It is 20-item questionnaire based upon the five-point Likert scale.

Scoring- After all the questions have been answered, the numbers for each response is added to obtain a final score. The higher score range indicates greaterlevel of addiction. Normal Range: 0-30 points. Mild Range: $31-$ 49 points. Moderate Range: $50-79$ points.

Severe Range: $80-100$ points. The Internet Addiction Test (IAT) is most widely used tool in studies conducted in the field of internet use. It is well validated in different studies across the globe.

Statistical Analysis- SPSS version 15 was used for the statistical analysis of data.

\section{Results}

In this study total 500 students participated. Out of which, maximum students were from $14-15$ years of age (74\%), followed by $16-17$ years of age (23.2\%) and 12 - 13 years of age (2.8\%). It included, $305(61 \%)$ boys and 195 (39\%) girls. 
Socio economic status: Maximum number of adolescents were from class III socio economic status 266 (53.2\%), 143 $(28.6 \%)$ were in class IV followed by $91(18.2 \%)$ in class II.

Level of internet addiction- Maximum adolescents had moderate (50 - 79) level of internet addiction test score i.e. 317 $(63.4 \%)$. Mild $(20-49)$ level of internet addiction test score was seen in $120(24 \%)$ adolescents and $56(11.2 \%)$ had severe $(80-100)$ test score. Only 7 students $(1.4 \%)$ were not having internet addiction $(0-19$ test score).

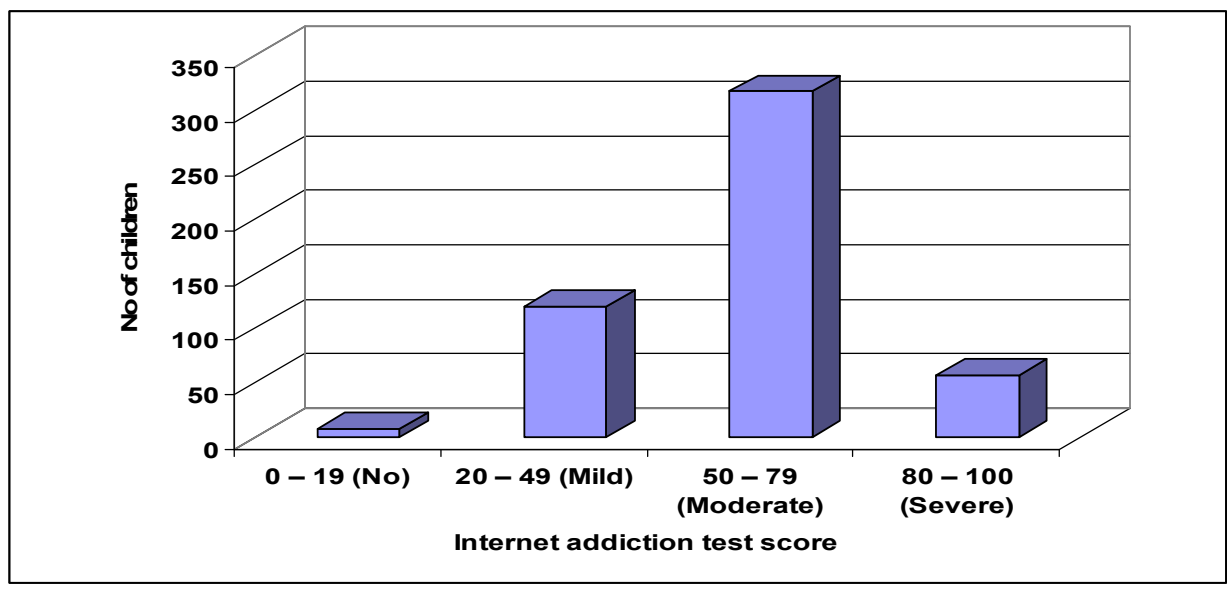

Figure-1: Level of internet addiction of adolescents in study group

Table-1: Comparison of internet addiction test score according to socio economic status in study group.

\begin{tabular}{|c|c|c|c|c|c|}
\hline \multirow{2}{*}{$\begin{array}{c}\text { Socio economic } \\
\text { status }\end{array}$} & & \multicolumn{2}{|c|}{ Internet addiction test score } & \multirow{2}{*}{ F Value } & \multirow{2}{*}{ P Value } \\
\cline { 2 - 4 } & $\mathbf{n}$ & Mean & SD & 525.28 & $<0.0001$ \\
\hline Class II & 91 & 78.31 & 15.134 & \\
\hline Class III & 266 & 64.11 & 6.476 & \\
\hline Class IV & 143 & 41.20 & 7.846 & & \\
\hline
\end{tabular}

In this study, significantly more internet addiction score was seen in the adolescents of class II socio economic statusthan class III andclass IV $(\mathrm{P}<0.0001)$.

Table-2: Comparison of internet addiction test score according to age in study group

\begin{tabular}{|c|c|c|c|c|c|}
\hline \multirow{2}{*}{ Age (Yrs) } & & \multicolumn{2}{|c|}{ Internet addiction test score } & \multirow{2}{*}{ F Value } & \multirow{2}{*}{ P Value } \\
\cline { 2 - 4 } & $\mathbf{N}$ & Mean & SD & 5.55 & 0.004 \\
\hline $12-13$ & 14 & 68.00 & 3.113 & \\
\hline $14-15$ & 370 & 61.01 & 15.433 & \\
\hline $16-17$ & 116 & 56.41 & 17.505 & & \\
\hline
\end{tabular}

In this study, significantly more internet addiction score was seen in the adolescents of 12 to 13 years of age as compared to 14 to15 years and 16 to 17 years. $(\mathrm{P}=0.004)$

Table-3: Comparison of internet addiction test score according to sex in study group

\begin{tabular}{|c|c|c|c|c|c|c|}
\hline \multirow[t]{2}{*}{ Parameter } & \multicolumn{2}{|c|}{ Male $(n=305)$} & \multicolumn{2}{|c|}{ Female $(n=195)$} & \multirow{2}{*}{$\begin{array}{l}\text { MW test } \\
\text { Z Value }\end{array}$} & \multirow[t]{2}{*}{ P Value } \\
\hline & Mean & $S D$ & Mean & $S D$ & & \\
\hline IAT score & 62.78 & 16.441 & 56.01 & 14.063 & 22.56 & $<0.0001$ \\
\hline
\end{tabular}

Boys had significantly more internet addiction score than girls in this study $(\mathrm{P}<0.0001)$ 
Editorial

\section{Discussion}

Digital revolution has contributed to increasing internet penetration. A number of studies have been conducted across the world, especially among adolescents with respect to internet addiction. This study is a preliminary step toward understanding the extent of internet addiction among school students in India. In this study total 500 students participated. Out of which, maximum students were from $14-15$ years of age $(74 \%)$, followed by $16-17$ years of age $(23.2 \%)$ and $12-13$ years of age $(2.8 \%)$.It included, $305(61 \%)$ boys and 195 (39\%) girls.

A wide range of prevalence of internet addiction has been reported in different studies, ranging from $0.2 \%$ to $36.7 \%$. The prevalence was $0.2 \%$ in Chinese adolescents [12] and $36.7 \%$ in Italian adolescents [13]. Though, both used same IAT scale, the difference in prevalence was due to criteria used for classifying internet addiction. In this study, maximum number of students were boys $305(61 \%)$ and $195(39 \%)$ were girls. A study conducted by Nalwa et al investigated the extent of internet addiction in school children in India [14]. The findings of the present study corroborate with previous study by Anderson KJ et alstating that addiction is more common in males than in females [15].

Kim et al studied that this gender disparity is explained partly on the basis of indulgence in different online activities by males and females Boys are more likely to use the net for entertainment purposes like gaming and cybersex, which are strongly associated with compulsive internet use [16, 17]. In this study we found that relationship between internet addiction and familyis stronger. Significantly more internet addiction score was seen in adolescents of Class II Socio economic statusthan class III and IV in this study $(\mathrm{P}<0.0001)$.

It might be due to easy availability of computers and internet accessibility for adolescents. Parents might be lacking the knowledge about the instructions to be taken for their children. In class III and IV large number of students gained access to the internet in internet cafes because of a lack of computers at home.

But Tsitsika et.al (2011) evaluate the psychosocial profiles and psychiatric co-morbidities associated with Internet Addiction among adolescents. A case-control study was conducted among 129 adolescents. They found that Internet addict and non-addict were similar in terms of area of residence and socioeconomic status.
That mean they didn't found any correlation between socio-economic status and internet addiction [18]. Many studies had shown that internet addiction among adolescentsare significantly associated with co-morbid psychiatric conditions, including depression, dysfunctional familial relationships, poor academic performance and engagementin high- risk behaviors

In present study out of 500 students maximum adolescents had moderate $(50-79)$ level of internet addiction test score i.e. 317 (63.4\%). Mild (20-49) level of internet addiction test score was seen in $120(24 \%)$ adolescents and $56(11.2 \%)$ had severe $(80-100)$ test score. Only 7 students $(1.4 \%)$ were not having internet addiction ( $0-19$ test score) and among adolescents with age group of 12 to 13years had significantly more internet addiction score than age group of 14 to 15 years and 16 to 17 years $(\mathrm{P}=0.004)$. This can be explained due to easy availability of internet through mobile phones and online gaming and poor self control in early adolescence. In a study by Smahel et al of a representative sample of Czech youths aged 12-26 years, the rates of IA did not differ by age, while an online questionnaire based study concluded that young people were significantly more likely to show addictive symptoms than were older people $[19,20]$.

A similar study by Pallanti et al found that the average age of students who have internet addiction is $16.67 \pm$ 1.85 [21]. It means that, adolescent who are addicted to internet, are normally in the age range of 14 years old to 18 years old which matches the age range in other studies.

Study by Casey et al showed thatonline communication application such as instant messaging and chatting bear a higher addictive potential than other internet application [22].

Furthermore, the immaturity of frontal cortical and subcortical monoaminergic brain system is hypo the sized to underlie adolescent impulsivity as a transitional trait behavior [22]. The neuro development process seems to be functional by enhancing the learning drive, on the other hand these processes may lead to an increased vulnerability to addictive behaviors in adolescent. Associations between aggression and Internet addiction disorder (IAD), which has also been linked with anxiety, depression, and impulsiveness is reported. Internet addiction also leads to sedentary lifestyle and lifestyle diseases. 
Editorial

\section{Conclusions}

Internet overuse in adolescents is increasing rapidly. In present study out of 500 students maximum adolescents had moderate (50-79) level of internet addiction test score i.e. $317(63.4 \%)$. Mild $(20-49)$ level of internet addiction test score was seen in $120(24 \%)$ adolescents and $56(11.2 \%)$ had severe $(80-100)$ test score. Only 7 students $(1.4 \%)$ were not having internet addiction $(0-$ 19 test score)

Internet addiction score was seen higher in adolescents of Class II Socio economic status than class III and IV in this study. This might be due to easy availability ofelectronic gadgets at home and lack of parental supervision

Out of 500 students maximum number of internet addiction was observed among boys $305(61 \%)$ as compared to 195 (39\%) girls.

Early adolescents withage group of 12 to 13 years had significantly more internet addiction score than age group 0 f 14 to 15 years and 16 to 17 years of age due to poor control.

Significance of the study- In the booming Era of internet, internet addiction is also being increasing parallely. It is associated with psychological and behavioral problems like depression, suicidal tendencies, violent behavior etc. Internet addiction can be prevented and reduced with the help of education about net safety, media screening, promoting mental health, public awareness on internet addiction etc should be done for adolescents and parents.

So all school students of different age groupsmust be screened for Internet addiction andabout pattern of internet use .It shouldbe first recognized in order to help themselves. Since, the prevention is better than cure.

Education about productive use of gadgets under strict supervision of parents should be encouraged

\section{Contribution by authors}

- Dr. Manu Batta and Dr.Kumar Gaurav have collected the data from school,Dr Rasika Bharaswadkar have compiled the data.

- Dr.Shailaja Mane and Dr.ShradhaSalunkhe have analyzed the data and written the manuscript.

- Dr Sharad Agarkhedkar(H.O.D) has constantly guided throughout the study.
Acknowledgements: I wish to express my heartfelt thanks and deep sense of gratitude to the principal and students of the school where this study was conducted.

Ethical Approval: The study was carried out after the approval from the Institutional Ethical Committee of Dr. D. Y. Patil Medical College, Hospital and Research Center, Pimpri, Pune.

Funding: Nil, Conflict of interest: None initiated, Perission from IRB: Yes

\section{References}

1. Internet Addiction: A Handbook and Guide to Evaluation and Treatment edited by Kimberly S. Young, Cristiano Nabuco de Abreu.

\section{2. http://www.internetworldstats.com/stats3.html}

3. Gold berg I. Internet Addiction 1996. [Last accessed on 20 jan2017].Available from:http://web.urz. uniheidel berg.de/Netzdienste/anleitung/wwwtips/8/addict.html .

4. Daniel T, Shek L, Rachel C, Sun F, Lu YU. Neuroscience in the 21 st Century from Basic to Clinical. 2 ended. New York: Springer Science+ Business Media LLC; 2013

5. Young KS. 1st Ed. New York: John wiley and Sons; 1998. Caught in the net: How to recognize the sings of internet addiction and a winning strategy for recovery.

6. Durkee T, Kaess M, Carli V, Parzer P, Wasserman C, Floderus Betal, Apter A, Balazs J, Barzilay S, Bobes J, Brunner R, Corcoran P, Cosman D, Cotter P, Despalins R, Graber N, Guillemin F, Haring C, Kahn JP, Mandelli L, Marusic D, Mészáros G, Musa GJ, Postuvan V, Resch F, Saiz PA, Sisask M, Varnik A, Sarchiapone M, Hoven CW, Wasserman D. Prevalence of pathological internet use among adolescents in Europe: demographic and socialfactors.Addiction. 2012 Dec;107(12):221022. doi: 10.1111/j.1360-0443.2012.03946.x.Epub 2012 Jul 26.

7. Tsitsika A, Janikian M, Schoenmakers TM, Tzavela EC, Olafsson K, Wójcik S, Macarie GF, Tzavara C, Richardson C. Internet addictive behavior in adolescence: a cross-sectional study in seven European countries. Cyberpsy chol Behav Soc Netw. 2014 Aug; 17 (8): 528-35. doi: 10.1089/cyber. 2013. 0382. Epub 2014 May 22. 
8. Tavakolizadeh J, Atarodi A, Ahmadpour S, Pourgheisar A. The prevalence of excessive mobile phone use and its relation with mental health status and demographic factors among the students of Gonabad university of medical sciences in $2011-2012$. Razavi Int J Med. 2014; 2(1): e15527.

9. Demirci K, Akgönül M, Akpinar A. Relationship of smartphone use severity with sleep quality, depression, and anxiety in university students. J Behav Addict. 2015; 4 (2):85-92. the main causes of Internet addiction.

10. Simon Kemp. Social, Digital and Mobile in India. 2014. Website: http://wearesocial.net/tag/india/ [Last accessed on 18th dec 2016]

11. Widyanto L, McMurran M. The psychometric properties of the internet addiction test. Cyberpsychol Behav. 2004 Aug; 7(4):443-50.

12. Lam LT, Peng ZW. Effect of pathological use of the internet on adolescent mental health: a prospective study. Arch Pediatr Adolesc Med. 2010 Oct; 164 (10): 901-6. doi: 10.1001/archpediatrics. 2010.159.

13. Milani L, Osualdella D, Di Blasio P. Quality of interpersonal relationships and problematic Internet use in adolescence.CyberpsycholBehav. 2009 Dec;12(6): 681-4. doi: 10.1089/cpb.2009.0071.

14. Nalwa K, Anand AP. Internet addiction in students: a cause of concern. Cyberpsychol Behav. 2003 Dec;6 (6): 653-6.

15. Anderson KJ. Internet use among college students: an exploratory study.J Am Coll Health. 2001 Jul;50 (1):21-6.
16. Kim EJ, Namkoong $\mathrm{K}, \mathrm{Ku} \mathrm{T}$, Kim SJ. The relationship between online game addiction and aggression, self-control and narcissistic personality traits. Eur Psychiatry. 2008 Apr;23(3):212-8. doi: 10.1016/j .eurpsy.2007.10.010. Epub 2007 Dec 31.

17. Siomos KE, Dafouli ED, Braimiotis DA, Mouzas OD, Angelopoulos NV. Internet addiction among Greek adolescent students. Cyberpsychol Behav. 2008 Dec;11 (6): 653-7. doi: 10.1089/cpb.2008.0088.

18. Tsitsika, A., Critselis, E., Louizou, A., Janikian, M., Freskou, A., Marangou, E., Kormas, G., and Kafetzis, D.A. (2011) Determinants of Internet addiction among adolescents: a case-control study. The Scientific World Journal: TSW Child Health\& Human Development, 11, 866-874. DOI 10.1100/tsw.2011.85.

19. Smahel D, Brown BB, Blinka L. Associations between online friendship and Internet addiction among adolescents and emerging adults. Dev Psychol. 2012 Mar; 48 (2):381-8. doi: 10.1037/a0027025.

20. Morrison CM, Gore H. The relationship between excessiveInternet use and depression: a questionnairebasedstudy of 1,319 youngpeople and adults. Psychopathology. 2010;43(2):121-6. doi: 10.1159/000277001. Epub 2010 Jan 23.

21. Nalwa K, Anand AP.Internetaddiction in students: a cause of concern.CyberpsycholBehav. 2003 Dec;6(6): 653-6.

22. Casey, B. J., Tottenham, N., Liston, C., \&Durston, S. Imaging the developing brain: What have we learned about cognitive development? Trends in Cognitive Sciences, 2005; 9, 104-110.

\section{How to cite this article?}

Mane S, Salunkhe S, Batta M, Agarkhedkar S, Kumar G, Bharaswadkar R. Internet addiction in school going adolescents of different socio economic classes in Western India. Int J Pediatr Res. 2018;5(2):60-65. doi:10.17511/ijpr.2018.i02.04. 